\title{
Paper 1 \\ Technologies for value creation: An exploration of remote diagnostics systems in the manufacturing industry
}

\author{
Katrin Jonsson, Ulrika H Westergren \& Jonny Holmström \\ Department of Informatics, Umeå University, Sweden
}

\begin{abstract}
With firms increasingly relying on ubiquitous computing to implement major business initiatives, it is becoming ever more necessary to understand the technological aspects of business developments. This paper analyzes the use of remote diagnostics systems in the manufacturing industry and discusses the opportunities and challenges for the early adopters. It pays specific attention to the impact on business aspects such as the value creation process consisting of relationships, roles, and architecture and the value proposal consisting of a business offer and customer value. The study shows how ubiquitous computing allows manufacturers to become remote service providers while customers can either become co-creators of value or passive receivers of created value. Ubiquitous computing also creates possibilities for the manufacturing industry to design new kinds of
\end{abstract}


business offers based on remote presence. Studying remote diagnostics systems shows that ubiquitous computing creates value when deployed in products, and not just in relation to individuals. Moreover, the design of the value creation process should not be limited to the single supplier or customer organization, as ubiquitous computing applications take no notice of organizational boundaries.

Keywords: ubiquitous computing, remote diagnostics systems, value system, value creation, value proposal, manufacturing industry

\section{Introduction}

With firms increasingly relying on ubiquitous computing to implement major business initiatives, it is becoming ever more necessary to understand the technological aspects of business developments. In this paper, we focus on ubiquitous computing and its business impact for organizations. We argue that innovations of such scale and complexity cannot be properly understood by focusing on the value the technology brings in relation to individuals. Instead, we argue for a focus on ubiquitous computing with particular emphasis on the way in which it is embedded in business contexts. To this end, we apply an integrative framework based on Porter's (1985) value chain framework building on the idea that the role and meaning of ubiquitous computing in business contexts cannot be researched without paying attention to value creation within and between organizational boundaries.

While Porter (2001) makes some sweeping generalizations about the possible transforming aspects of the Internet in relation to business, he pays little attention to the role that information technology (IT) plays in changing business organizations. In contrast, Lyytinen \& Yoo (2002b) highlight the transformational aspects of IT on business organizations as an important field to explore, especially with the employment of ubiquitous computing.

In the research on emerging technologies, it is important to pay attention to the ongoing processes that precede the final applications. Lyytinen \& Yoo (2002b) recommend that 'IS researchers should be actively involved in studies where technologies are being built and tried out - not after the fact when they enter the market'. In view of this ambition, we have chosen to concentrate our efforts on a manufacturing company in their ongoing process of designing a remote diagnostics system with the business in mind. The rationale behind this approach is our aim to capture experiences and expectations of designing ubiquitous computing in order to answer our question: how can ubiquitous 
computing influence businesses in the manufacturing industry? The main aspects considered are the value creation process consisting of relationships, roles, and architecture and the value proposal consisting of a business offer and customer value. On the basis of our empirical findings, the article discusses important insights related to the business potential of ubiquitous computing.

By viewing the technology from a value-creation perspective, the paper contributes to the understanding of ubiquitous computing in relation to industry structures and value chains, a field that is unexplored (Lyytinen \& Yoo, 2002b). Research on industrial applications of ubiquitous computing is limited (Lampe et al., 2004), and because manufacturing companies are faced with the decision of whether or not to incorporate new technology into their products (Österle, 2001), this paper is of interest for the research community as well as for practitioners.

The paper proceeds as follows: In section 2 we review the literature on ubiquitous computing in business settings and the value system. Section 3 describes the research design. In section 4 we introduce the studied organization and present a number of internal and external problems experienced by the company before we go on to describe and analyze two possible technological solutions. In section 5 we discuss the impact of the technology on businesses, and finally, the paper concludes with a summary of the findings in section 6 .

\section{Ubiquitous Computing}

The development of IT with increased computing power, smaller devices and improved network capabilities has radically affected how and where computing technology can be used. Terms like traditional business computing, mobile computing, pervasive computing and ubiquitous computing are used to describe the progress of technology and its usage (Lyytinen \& Yoo, 2002a). In this paper, the term ubiquitous computing refers to technology embedded into products and the environment (Lyytinen \& Yoo, 2002a), supporting collection of contextual data (Henfridsson \& Lindgren, 2005).

Ubiquitous computing allows for data-capturing processes that can take place seamlessly and unobtrusively (Araya, 1995). Data such as identity, location, status and time can be captured to provide information about the current context (Dey et al., 2001). Identity refers to unique identifiers that enable the separation of entities; location includes geographical coordinates, spatial relations as well as the orientation of an entity; status identifies characteristics of the entity that can be sensed; 
and time gives a timestamp or a time span and helps keep track of events in the context. Moreover, the contextual data can be correlated with three different entities - places, people and things (Dey et al., 2001). The predominant research on ubiquitous computing so far focuses on the technology in relation to people and their identity and location (Abowd \& Mynatt, 2000; Jessup \& Robey, 2002; Cousins \& Robey, 2005; Henfridsson \& Lindgren, 2005). The current research is thus limited both in terms of type of contextual data captured and its source.

Remote diagnostics systems are a specific type of ubiquitous computing embedded into a product and capturing contextual data (Jonsson \& Holmström, 2005). The products are provided with embedded sensors that enable automatic data collection and remote monitoring of their status and how it changes over time. Distant technicians monitor variances in the collected data to determine the need for product maintenance. In contrast to the predominant research on ubiquitous computing applications, the study of remote diagnostics systems focuses on products and has a broad focus on context, where identity, location, status and time are all included to provide contextual data.

\subsection{Ubiquitous computing in the business environment}

Ubiquitous computing can have a direct and strong impact on business processes through the possibilities of automatic identification, localization and sensor technology (Strassner \& Schoch, 2002). Supportive processes, innovation, supply chain management and customer relationship management are all examples of processes that can be affected by the technology (Strassner \& Schoch, 2002; Avital \& Germonprez, 2003).

Cost reduction as a consequence of ubiquitous computing use has been observed in a study of aircraft maintenance (Lampe et al., 2004), where a ubiquitous computing tool inventory system improved planning and documentation, made the work more time efficient and led to higher quality of the maintenance. Ubiquitous computing can also enhance sales and business opportunities and lead to new revenue-generating businesses (Fleisch, 2001). The continuous data flow from ubiquitous computing applications enables a seamless provision of services at any time and any place, that can even be coordinated in real time. For example, services can be offered to customers while they are on the move (Yoo \& Lyytinen, 2003). In the consumer market, ubiquitous computing can serve as a tool for providers, enabling them to work with the customers in new ways and to strengthen the relationship 
(Kourouthanassis \& Roussos, 2003). Moreover, ubiquitous computing creates a media-rich channel between companies and their customers, which creates new opportunities for customer interaction and a need to redesign customer-service processes (Gershman \& Fano, 2005).

In a study of the insurance industry, Müller \& Zimmermann (2003) found that ubiquitous computing has the potential to change businesses fundamentally as the insurance companies are provided with real-time information about the customers' behaviour. They identified three areas on which ubiquitous computing has a business impact: on the value creation structures, on the value proposition and on customer relations. The information provided by the ubiquitous applications opens up new possibilities for risk evaluation and product customization, leading to a redesign of existing value proposals. Moreover, as data can be easily captured and transferred, new actors who possesses information about the insurance customer will be involved, which will change the traditional value creation structures. With new actors in the value creation process, customer relations will change and new channels will be available for interaction.

Even though ubiquitous computing is optimistically forecasted to enable new business opportunities, there are few studies of this technology in business settings (Fleisch \& Tellkamp, 2003). Müller \& Zimmermann (2003) point to the need for more research on the impact of ubiquitous computing on value creation structures, value proposals and customer relations as the changes may be fundamental, for example in the financial industry. In this paper, we adopt this approach to study the business impact of ubiquitous computing and apply it in another industry: the manufacturing industry. In the following section, we will define the value creation structures, value proposals and customer relations based on the value system framework.

\subsection{The value system}

The value system presented by Porter (1985) depicts value creation as a larger stream of activities that create and deliver value. The value system helps in understanding the networked business setting surrounding a business organization, as focus is on a network level rather than on the single organization. With the value system in mind, it becomes possible to explore how value could be created not only within a company but also in relation to, and in the linkages between, different companies in the value system.

In the present study, we use the term value system to refer to the context in which the business organization acts to create value. In the 
literature, names like value systems, value networks, value nets, market networks and value creating networks are terms used to describe this phenomenon (Kothandaraman \& Wilson, 2001).

Kothandaraman \& Wilson (2001) identify three important concepts characterizing a value system: core capabilities, relationships and superior customer value. The core capabilities of the firms and the relationships influence the way value is created. Stanoevska-Slabeva \& Heitmann (2003) identify a value system framework based on business model components. Four elements are included: the customers and their benefits, the business offer (products and services), the value exchange network and the internal architecture. The first two elements define the scope and the outcome of the value system, while the last two explicate the way value is created. A comparison between the two value system frameworks presented by Kothandaraman \& Wilson (2001) and Stanoevska-Slabeva \& Heitmann (2003) shows similarities. Two main categories can be identified: the first one concerns how value is created and the other concerns the generated value proposal.

\section{The value creation process:}

Relationships and roles: Identifies other actors involved in the value creation process and their roles and relationships. Could be partners, suppliers, distributors as well as the customer himself, who all cooperate in order to create value (Normann \& Ramirez, 1993; Stabell \& Fjeldstad, 1998).

Architecture: describes key activities in the value creation process as well as needed resources and capabilities.

\section{The value proposal:}

Business offer: specifies the generated product or service.

Customer value: describes the customer needs and benefits of using the offered product or service.

The impact of ubiquitous computing on value creation structures, value proposals and customer relations as studied by Müller \& Zimmermann (2003) is in this study further developed with the value system framework. Rather than focusing exclusively on the categories identified by Müller \& Zimmermann (2003) the whole network involved in the value creation is under critical scrutiny. In the next section, we will 
explore our research question: how can ubiquitous computing influence businesses in the manufacturing industry? We will do so by examining a study at MacGregor Cranes and the possibilities and constraints of a remote diagnostics system.

\section{Research Methodology}

This paper reports on a study at MacGregor Cranes, a manufacturer of shipboard cranes. It forms part of a wider research project called Industrial City 2.0, which is a collaborative project between our research group and a number of organizations that all share a common interest in remote diagnostics systems. From a research perspective, we are interested in studying the systems in a practical setting, while the companies are interested in deploying them in their business in a profitable way. By organizing projects this way they can work as a shared space in which research efforts as well as practice initiatives can blend in a fruitful way (Mathiassen, 2002).

\subsection{Research site}

The study employed an interpretive case study approach (Walsham, 1993; Klein \& Myers, 1999) at MacGregor Cranes. The rationale behind selecting the research site was the willingness to cooperate, the availability of multiple sources and the possibility of purposeful sampling (Yin, 1989; Peppard, 2001). MacGregor Cranes had by the time of the study started to investigate the commercial possibilities with a remote diagnostics system, which gave us the possibility to collect purposeful data.

The study was conducted in 2002-2003 at MacGregor Cranes, during which we followed the initial discussions related to designing and installing a remote diagnostics system into shipboard cranes. This was a project for the after-sales division together with selected people from the technical group. Our study is based on MacGregor's process of assessing the possibilities and constraints of the remote diagnostics system in the value creation process.

\subsection{Data collection}

As typical in case studies, data was collected through a mixture of techniques (Yin, 1989). Besides data collected from company meetings and semi-structured interviews with selected respondents, documents from the after-sales division, and minutes of internal meetings and presentations were examined. Together, all these sources form the empirical base of the study. All data collection was performed by the first 
and the second authors. We attended five 3-hour meetings where MacGregor representatives from the after-sales division and the technical group were discussing and evaluating different business offers and technological solutions. The members of the group were the director of after-sales, the director of services, the director of modernization/technology development, the senior designer and project manager for the new crane control system, CC2000, and one person from systems design and development. These were the people that MacGregor Cranes had chosen to be responsible for this specific project. During the meetings field notes were taken, and we were also allowed to ask questions to bring clarity to the topics discussed.

In order to further increase our understanding of MacGregor's remote diagnostics project, we conducted individual interviews with the first four members of the group. We chose to include all representatives from the after-sales division, as they were focused on the business side of the project, and one representative from the technical group, who provided insights into the technological possibilities and constraints of the system. The interviews all lasted between 2 and 3 hours and were performed on site at MacGregor Cranes. There was one structured part with a framework of questions concerning the value creation process, the value proposal and the technology's employment, followed by an unstructured element with follow-up questions and questions that emerged from previous interviews, documents and meetings. All interviews were audiorecorded and then transcribed. In this study, the focus was exclusively on MacGregor's representatives' accounts of the system and their business processes as this was how MacGregor's development process took place.

\subsection{Data analysis}

The results of this study were developed in a three-stage analysis. During stage 1, the first two authors read through all the data material. While reading, notes were taken to summarize the material.

In stage 2 of the analysis, the first two authors met and compared notes and performed a cross analysis to find similarities and differences across the different data sources. We sought to retain a large degree of theoretical flexibility to ensure that the emergent constructs were built on the empirical data and thus did not use any formal hypotheses to guide the analysis (Eisenhardt, 1989). Based on the data, we identified a number of problems that MacGregor Cranes hoped to solve with the development of the remote diagnostics system. These problems were divided into two categories: external and internal. Furthermore, two different technical solutions of the remote diagnostics system were 
envisioned from the technical staff. In the two value systems presented later in this paper, the two technical solutions are brought together with the value creation possibilities envisioned by the respondents at MacGregor Cranes.

We proceeded with the third stage of the analysis by using the value system's framework with its focus on value creation and value proposal to provide some structure to the analysis. The data was thus grouped into two different value systems, where the value creation processes, the value proposal and their relation to technical considerations was in focus. We then examined the two proposed value systems in order to shed light on how remote diagnostics systems impact businesses in the manufacturing industry. During this stage, we attempted to move away from single events and initial impressions (Eisenhardt, 1989) and to generalize beyond the data (Olaisen, 1991).

\subsection{Data presentation}

In this paper, the empirical data is presented within the context of identified problems and the two proposed value systems. Some specific quotations from the interviews are used to highlight certain discussions, but for the most part, the material constitutes the overall findings from the empirical base. The study is based on the MacGregor representatives' different accounts of their experience with, and knowledge of, after-sales work and remote diagnostics systems. To view a case through the perspective of the study's participants is at the very basis of interpretive research (Orlikowski \& Baroudi, 1991). The internal and external problems and thoughts on value creation as presented within this paper have thus emerged from the data sources and are analyzed based on the meanings that the MacGregor project members ascribe to them.

As recommended by Miles \& Huberman (1994, p. 278), a preliminary copy of the results was presented to, and circulated among, the interview respondents to ensure credibility and to increase the internal validity of the research. Comments and suggestions by the respondents - both on the written report and on an oral presentation given at the company headquarters - were incorporated into the research report.

\section{MacGregor Cranes at a Crossroads: Exploring Two Value Systems}

MacGregor Cranes is a manufacturer of different types of cranes used in the shipping industry. The company is a part of the larger MacGregor Group that includes manufacturers of hatch covers, shipboard elevators, galleys, etc. Service and maintenance of cranes is the indisputably biggest 
business in the after-sales sector for MacGregor Cranes. Service agreements are viewed as an important tool in creating strong relationships with customers, and the company therefore strives to increase the number of signed agreements.

In 1997, MacGregor defined service as the ability to give its customers the freedom to concentrate on pursuing cargoes and maximizing profitable operations, knowing that their fleet's key systems are receiving attention from a specialist. By designing and installing a remote diagnostics system into the cranes, MacGregor Cranes envisions giving its customers improved service related to after-sales. In a staff magazine, the company's president says:

The message is the same today [as in 1997] but we now have the technology [. . . enabling us to offer real-time condition monitoring of our products wherever in the world they are operating [...] live condition-monitoring is the last link to complete care [...] the idea is not new but we had to wait for new technology to make it work. (president, MacGregor Group).

During the design process, a number of problems related to after-sales were identified that when solved could contribute to improved uptime of the customers' equipment.

\subsection{Problems related to the after-sale services at MacGregor Cranes}

The after-sales department at MacGregor Cranes is continually working towards extending its market share. This is done in part through selling spare parts and upgrades, but mostly through performing service and maintenance. The main goal for the service organization is to minimize operational hold-ups as a result of the cranes not working properly. By keeping the uptime at a high level, value could be created for the customers (Armistead \& Clark, 1991). Based on the experience of the MacGregor staff, a number of problems connected to performing satisfactory service and maintenance have been identified. These problems serve as a good base in understanding how a remote diagnostics system could influence the way services are performed today. The problems are divided into two categories: external problems that have to do with the customer's organization and internal problems that are tied to MacGregor's own service organization.

\subsubsection{External problems}

- Division of responsibilities: On the ships, non-technical staff has the responsibility of servicing the crane without having the appropriate 
education and knowledge for the job. This often leads to neglected or badly performed maintenance.

- A complex way of information handling: Information regarding crane problems is often mediated from the crane driver to the helmsman, who in turn might report it to the ship owner before the information comes to MacGregor. Because of this, the information is often brief and sometimes distorted. At MacGregor, this results in endless phone calls, faxes, and emails to and from the ship with complementary questions in order to get more information about the error.

- Errors go undetected or unreported: The person driving the crane is a docker who is hired temporarily when the ship is in port. Consequently, the crane driver does not have any responsibility for the crane's functionality, which means that there is no guarantee that any problems will be discovered and reported to the helmsman. An experience that the technicians at MacGregor often faces is that the members of the ship's crew do not climb up the crane and check the parameters in the control system, which makes it hard to detect problems early on before something really breaks and the crane stops working.

- Language problems: As MacGregor Cranes operates in several different countries and cultures and has contact with people of various technical backgrounds, there is the possibility that language barriers arise, which makes the error-identification process more difficult. If the problem cannot be solved over the phone or via fax or email, a service technician is sent to the ship. This is an expensive solution for MacGregor and the customer, and it is important that the communication has been satisfactory so that the technician does not bring the wrong tools and spare parts with him.

\subsubsection{Internal problems}

- Time leakage: Many of the technicians have a long background with the company and have created long-lasting relationships with the customers. This also means that when problems arise, the customers call the technician directly instead of the support desk. The technicians all admit that they spend time giving the customers free support via phone and email. This kind of service does not generate 
any direct income but could, however, contribute to goodwill, which is difficult to measure.

- Knowledge recycling: Today, MacGregor has the beginnings of a kind of database that consists of logs that the technicians send to company headquarters after every visit to a crane. This kind of information is, for example, valuable if MacGregor finds out that many cranes from the same runs have common errors. However, the database is not being used to its full potential and updates are slow.

- Feedback from the field: Today, it is difficult for MacGregor to get feedback from the field about the cranes' conditions and how they are used. This kind of information is valuable in product development because it helps to design cranes that meet actual needs and usage.

In the assessment of the technology's possibilities, MacGregor envisioned two different technological solutions where data flows in different ways. As ubiquitous computing is a technology that brings with it a potential to change production, products and services connected to products, particular attention is put on the technological possibilities and limitations, for instance how data is transported, where the processing power should be and who has access to the data. Each solution results in different streams of information, leading to different value proposals and value creation processes, and accordingly solves different problems and creates different values.

\subsection{Value system 1}

\subsubsection{The value creation process}

The basic architecture in this technical solution is a system where the crane is provided with sensors that register data about the crane's condition, which is then transferred to the crane control system, CC2000, where it is stored temporarily. The sensors register data about the temperature, the pressure, the speed of the crane and the time of use. The control system is in turn provided with a GSM or a satellite modem to transfer data to MacGregor Cranes where it will be analyzed to find out the crane's condition (Figure 1).

With the remote diagnostics system we will be able to see urgent problems, but also to monitor pressure and more long-term parameters. If the pressure begins to drop it is sometimes an 
indication that something isn't functioning well. With that information in mind we can access the logs to continue the analysis (director of modernization, MacGregor Cranes).

Urgent problems or errors could be discovered by occasional readings of different parameters, but in order to prevent breakdowns, MacGregor will also perform analyses of longer time sets to draw conclusions about what is about to happen. In this solution, MacGregor will act alone in processing the collected data. The customer will be rather passive, either receiving a report with detected problems or, depending on the service agreement, waiting for MacGregor to take care of the maintenance.

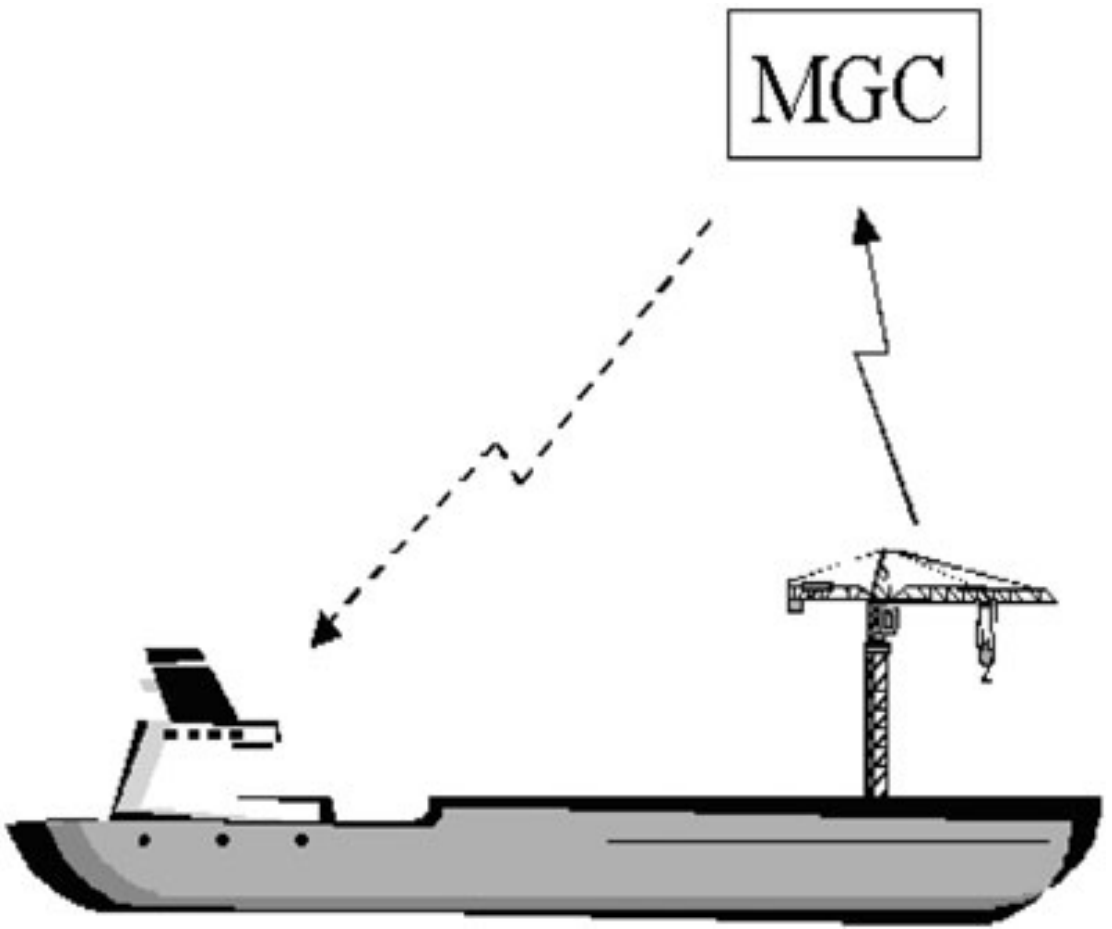

Figure 1. A ubiquitous information environment connected to MacGregor Cranes.

\subsubsection{The value proposal}

Today, the only way of getting direct information about a crane's condition is by physically being there. As it is very expensive to send a technician to the ship, many customers are reluctant to pay the price for service from MacGregor and turn to a local business instead. With this remote diagnostics solution, however, it is possible to monitor the equipment from a distance, which reduces costs and gives access to new 
kinds of information. Taken together, this makes it possible to calculate new kinds of offers. The director of modernization envisions the remote diagnostics system as follows:

Sometimes we ask the customer to climb up in the crane to check some parameters. But if we could get access to the crane's parameters with the remote diagnostics system, it would be like opening the bible (director of modernization, MacGregor Cranes).

Data about the crane's condition is a valuable source in planning maintenance. It allows condition-based maintenance that aims at predicting and preventing errors, which is valuable for the customer because unplanned operational hold-ups are very expensive. One way of creating new business offers with this solution is to incorporate it into traditional service contracts where MacGregor offers services based on crane monitoring. It also opens up for new types of service agreements, for example extended warranty if the customer lets MacGregor take care of all maintenance. Another more internal benefit of sending operational data directly to MacGregor is the possible use of data in product development. Potential product problems can be detected early on and avoided in further production.

In the previous section, a number of internal and external problems were described. Table 1 lists the problems and indicates whether or not this solution can reduce them in some way.

\begin{tabular}{|l|l|}
\hline Problems & Influence \\
\hline Division of responsibilities & No \\
\hline A complex way of information handling & Yes \\
\hline Errors go undetected or unreported & Yes \\
\hline Language problems & Yes \\
\hline Time leakage & Partly \\
\hline Knowledge recycling & Yes \\
\hline Feedback from the field & Yes \\
\hline
\end{tabular}

Table 1. The solution's potential influence on experienced problems

The remote diagnostics system in this solution can create value for the customer as well as for MacGregor. The most obvious value to the customers is the potential of minimizing operational hold-ups. The technology could also be helpful in solving many of the problems that MacGregor experiences today. The complexity of information handling could be reduced because MacGregor gets direct access to operational 
data instead of receiving information and error descriptions via many individuals. The regular monitoring of the crane also reduces the problem of an external person operating the crane because problems can be detected even if this person does not report them. Language problems could also be reduced because of the direct access to crane data. The problem with time leakage could partly be reduced because the time it takes to do analyses will be charged and the time it will take to search for errors can be reduced. The director of modernization at MacGregor sees a potential value for the technicians:

If you had this information [from the remote diagnostics system] before you visited the customer you would be better prepared. The technicians have to bring the right tools and spare-parts with them (director modernization, MacGregor Cranes).

By opening up the possibility of preventive maintenance, the planning horizon at MacGregor can also be lengthened, which would provide the company with a more manageable service organization. The feedback from the field would definitely be improved with this solution and the data could be a good source for knowledge recycling because it can be stored and used when future problems arise.

\subsection{Value system 2}

\subsubsection{The value creation process}

As in the first solution, the crane is provided with a number of sensors that register data about the crane's condition. What differentiates this solution from the previous one is that the control system is connected to the customer's ship office instead of MacGregor Cranes (Figure 2). In the ship's office there is a computer that analyzes the data and either presents it to the technical management in the office or sends it to other parties. With this architecture, there is no direct communication channel to MacGregor; the company can only receive data indirectly if the customers choose to send it. Therefore, the customer can choose to send the data to another service provider. 


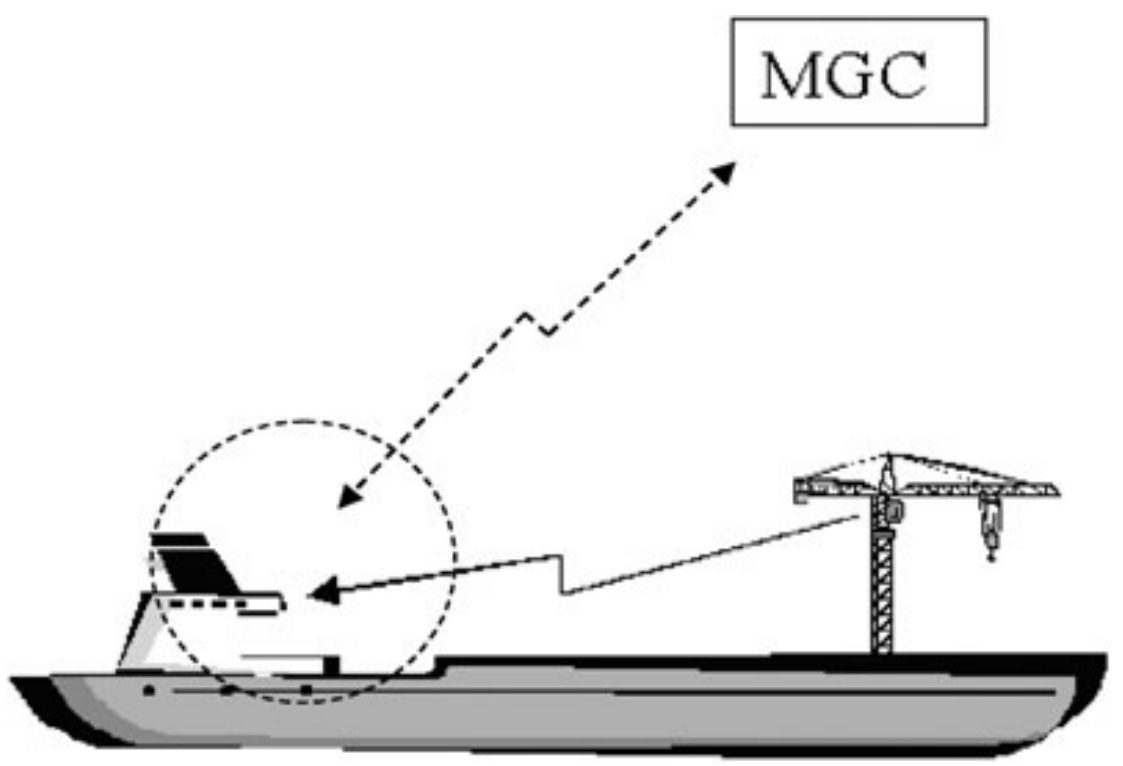

Figure 2. A ubiquitous information environment connected to the ship's office.

MacGregor's role in this solution will be to assist the customers when a problem arises that they cannot handle or identify on their own. The director of after-sales says that:

With the remote diagnostics system the technician maybe doesn't need to visit the ship. Maybe he can guide the customer to adjust a certain wheel to solve the problem. Then you see an obvious value to the customer who saved a lot of money. You should just go there when it's needed (after-sales manager, MacGregor Cranes).

However, the data will be a good base for MacGregor too when the customers choose to send data to MacGregor. In this solution, the customers can take a more active role in their own maintenance process and it will not lock them to a certain supplier.

\subsubsection{The value proposal}

The purpose of using data to provide condition-based maintenance will remain in this solution, but focus is put on improving the customer's own service organization. The system is used to provide the customers with better and more information about their own equipment, which will be valuable from a learning perspective. The senior designer at MacGregor says: 
The customer value is provided via the display [in the ship's office] where they can see what happens with the cranes and get alarms for example for exceeding maximum weight (senior designer, MacGregor Cranes).

As in the first model, MacGregor does not intend to sell the system; instead, it is to be incorporated in some kind of service agreement as they, of course, want to be the maintenance supplier and create a longlasting relationship with the customers.

The remote diagnostics system in this second solution mainly creates value for the customers by minimizing the number of operational holdups. This model does, however, also provide the customers with a better surveillance of their own crane. Instead of only providing the customer with a crane, MacGregor provides a new way of organizing the information flow so that it is directed towards the right group of people. The director of services argues that:

If the information was displayed in the ship's office the right people would get access to it, which could improve both the maintenance and the regularity (director of services, MacGregor Cranes).

The system also creates value by allowing the customers to learn more about the crane through the direct access to data. In addition, the system also helps reduce some of the problems presented in section 4.1. Table 2 shows how this way of organizing the data flow potentially influences the problems listed earlier.

\begin{tabular}{|l|l|}
\hline Problems & Influence \\
\hline Division of responsibilities & Yes \\
\hline A complex way of information handling & Yes \\
\hline Errors go undetected or unreported & Yes \\
\hline Language problems & Yes \\
\hline Time leakage & Partly \\
\hline Knowledge recycling & Partly \\
\hline Feedback from the field & Partly \\
\hline
\end{tabular}

Table 2. The solution's potential influence on experienced problems

The problems experienced with the division of responsibilities could be reduced with this solution. When data is transferred directly to the ship's office where the staff with the proper technical knowledge is located, appropriate action can be taken. The handling of information will not 
have to go through many different organizational layers, which reduces the complexity that has been experienced. As the system allows the technical staff in the ship's office to monitor the crane, the problem with errors being undetected or not reported because of an external person operating the crane could be reduced. The language problems could also be minimized because the data serves as a good base in the process of error seeking. By improving the process of seeking errors, time spent on that today can be reduced, which partly reduces the time leakage at MacGregor. As MacGregor will only receive data occasionally when the customers choose to provide them with it, this model does not provide them with the same opportunities to get feedback from the field and to recycle knowledge as the first solution.

\section{Discussion}

This paper sought to explore how ubiquitous computing can influence businesses in the manufacturing industry. The previous section has presented two solutions for understanding the value creation and value proposals enabled by remote diagnostics systems. These solutions provide alternative opportunities associated with the use of ubiquitous computing. They illustrate how the value proposals enabled by the system can create not just customer value but also manufacturer value by offering solutions to a range of internal and external problems. However, there is a danger in focusing exclusively on the potential benefits of the incorporation of new technology. Therefore in this section the scope is expanded to include potential risks associated with such incorporation.

\subsection{Value creation with ubiquitous computing}

Both solutions presented in this paper are based on the premise that ubiquitous computing will bring a shift in the value creating process. The relations and roles in the value creation process differ between the two solutions. Both solutions are based on the data channel from the cranes enabled by the remote diagnostics system. The information is then no longer carried by different individuals or connected to certain occasions; instead, data is transferred by the system with no notice taken of organizational boundaries or settings. In the first solution, MacGregor manages the direction of the flow. They can allow for certain data to turn around and flow back to the customer, while some data will flow to internal divisions at MacGregor, for example to the service division or the product development team.

In the second solution, the customers will take the role of director, deciding which path the data should follow. They can choose to let data 
flow internally in order to enhance maintenance processes and usage, or externally to MacGregor to draw benefits from their expertise.

Besides the role ascribed to the customer, the solutions also differ in terms of the view of the customer. As outlined in the first section, the incorporation of technology into the service process does not fundamentally change the process; instead, the system improves the way it is performed. As the customer has a rather passive position in the value creation process, he or she is best described as a consumer. The second model, however, uses the system in a way that instead of only improving the way service is performed allows for a new flow of information that puts focus on the customers and their own service processes. Instead of transferring data away from the ship to MacGregor, the data is kept and partly analyzed on board where the maintenance actually has to be performed. Focus is mainly on the customer's own way of organizing information and maintenance work, and the business process therefore mainly takes place within the customer's organization, although it is in collaboration with MacGregor. The customers are then no longer just consumers of value; instead, they are supposed to take an active role and be part of their own value creation process; they become a co-creator in the value creation process.

Besides the key activities performed by MacGregor and the customer as previously described, the remote diagnostics system constitutes an important part of the architecture. When deploying a remote diagnostics system at a customer's site, data connections allow both collection and transfer of data that can be valuable either to the customer or the supplier. With ubiquitous computing, value creation thus takes place not only within but also outside an organization as the technology takes no notice of such boundaries. As organizational boundaries are transgressed, the design of the value creation process should not be limited to the single supplier or customer organization, as parts of the value creation process could then be overlooked.

\subsection{Ubiquitous computing and the value proposal}

MacGregor sees the remote diagnostics system as offering potentially improved services and maintenance. With real-time monitoring, the cranes will get attention from MacGregor's specialists and the system is viewed as the last link to provide complete care of the cranes wherever they are in the world. Complete care will be a broad after-sale offer where MacGregor will take more responsibility for keeping the cranes up and running. 
In terms of created value, both proposals offer solutions to a range of internal and external problems, which can create value for the customers as well as for MacGregor. Both solutions have the potential to create value to the customers by reducing the number of operational hold-ups. However, the first model can be said to create more direct value for MacGregor as it can solve or reduce all of their internal problems. The second model has a clearer focus on the customers and can solve the experienced external problems while partly solving MacGregor's internal problems. The internal and external perspectives on value creation help to reveal each partner's benefits of the system as their different roles and relations are exposed.

Although there seem to be a lot of possibilities, there are also potential risks associated with the use of remote diagnostics systems for new value proposals, based upon the idea of direct access to customer data. Earlier research shows that in order for technology-enabled business processes to be successfully implemented in the customer organization, it is important that the provider understands the perceptions and perspectives of the customers (Walker \& Craig- Lees, 1999). Otherwise, there is a risk that the use of technology will depersonalize the service experience and cause frustration with the customers (Walker \& CraigLees, 2000). This is perhaps even more important to consider with the use of ubiquitous computing because it contributes to the delivery of remote services, taking place unobtrusively in the customer's organization.

Another important aspect that both MacGregor and their customers have to keep in mind is the remote diagnostics system's constraints. The system will only detect what it is designed to detect and there will always be errors that are beyond the reach of the installed sensors. Furthermore, the system itself will constitute a potential source of error. If these constraints are neglected, the value proposal will in the worst case create untenable expectations.

As the use of remote diagnostics is based on data logging, it means that it is possible for MacGregor to detect incorrect use of the crane or neglected maintenance. It is therefore important that one does not forget the question of privacy as this can have a major impact on how the system is adopted. Another risk to the manufacturer that is associated with the second solution is that the customer has direct access to the operational data. This also means that they can enlist the aid of other service organizations to analyze the data and perform maintenance. That would imply that MacGregor could potentially lose customers because of 
the arrival of new actors who use the technology for their own benefit. This can partly be handled in service agreements, but it is a potential risk.

\section{Conclusions}

This paper has explored how ubiquitous computing can influence businesses in the manufacturing industry. The main aspects considered are the value creation process consisting of relationships, roles, and architecture and the value proposal consisting of a business offer and customer value.

This study shows how ubiquitous computing in the form of a remote diagnostics system can serve as a base for the value creation process. The continuous information flow allows manufacturers to become remote service providers and the customers can either become co-creators of value or receivers of created value. As ubiquitous computing applications take no notice of organizational boundaries, the design of the value creation process should not be limited to the single supplier or customer organization, as parts of the process could then be overlooked.

Ubiquitous computing has also been shown to create possibilities for the manufacturing industry to design new kinds of business offers based on remote presence. The business offers enabled by the system can create not just customer value but also manufacturer value by offering solutions to a range of internal and external problems.

Studying remote diagnostics systems shows that ubiquitous computing creates value when deployed in products, and not just in relation to individuals. Assessing ubiquitous computing for business purposes thus requires a focus on the environment where technology embedded in products plays a role.

\section{References}

Abowd, G. \& Mynatt, E. (2000) Charting past, present, and future research in ubiquitous computing. ACM Transactions on Computer-Human Interaction, 7, 29-58.

Araya, A. (1995) Questioning ubiquitous computing. Paper presented at the Proceedings of the 1995 ACM $23^{\text {rd }}$ Annual Conference on Computer Science. [WWW document]. URL http://doi.acm.org/10.1145/259526.259560. Nashville, TN, USA, 28 Feb-2 March. 
Armistead, C. \& Clark, G. (1991) A framework for formulating aftersales support strategy. International Journal of Operations \& Production Management, 11, 111-124.

Avital, M. \& Germonprez, M. (2003) Ubiquitous computing: surfing the trend in a balanced act. Paper presented at the Workshop on Ubiquitous Computing, Cleveland, OH, USA, 23-26 October.

Cousins, K. \& Robey, D. (2005) Human agency in a wireless world: patterns of technology use in nomadic computing environments. Information and Organization, 15, 151-180.

Dey, A.K., Abowd, G. \& Salber, D. (2001) A conceptual framework and a toolkit for supporting the rapid prototyping of contextaware applications. Human-Computer Interaction, 16, 97-166.

Eisenhardt, K.M. (1989) Building theories from case study research. Academy of Management Review, 14, 532-550.

Fleisch, E. (2001) The financial business case for ubiquitous computing business applications. M-Lab Working Paper no. 6. University of St. Gallen, St. Gallen, Switzerland.

Fleisch, E. \& Tellkamp, C. (2003) The challenge of identifying value-creating ubiquitous computing applications. Paper presented at the UbiComp Workshop on Ubiquitous Commerce, Seattle, WA, USA, 12-15 October.

Gershman, A. \& Fano, A. (2005) Examples of commercial applications of ubiquitous computing. Communications of the ACM, 48, 71.

Henfridsson, O. \& Lindgren, R. (2005) Multi-contextuality in ubiquitous computing: investigating the car case through action research. Information and Organization, 15, 95-124.

Jessup, L. \& Robey, D. (2002) The relevance of social issues in ubiquitous computing environments. Communications of the ACM, 45, 88-91. 
Jonsson, K. \& Holmström, J. (2005) Ubiquitous computing and the double immutability of remote diagnostics technology: an exploration into six cases of remote diagnostics technology use. In: Designing Ubiquitous Information Environments Sociotechnical Issues and Challenges, Lytinnen, K., Yoo, Y. \& DeGross, J. (eds), pp. 153-167. Kluwer: London, UK.

Klein, H.K. \& Myers, M.D. (1999) A set of principles for conducting and evaluating interpretive field studies in information systems. MIS Quarterly, 23, 67-93.

Kothandaraman, P. \& Wilson, D.T. (2001) The future of competition: value-creating networks. Industrial Marketing Management, 30, 379-389.

Kourouthanassis, P. \& Roussos, G. (2003) Developing the user experience in ubiquitous commerce. Paper presented at the Ubicomp Workshop on Ubiquitous Commerce, Seattle, WA, USA, 12-15 October.

Lampe, M., Strassner, M. \& Fleisch, E. (2004) A ubiquitous computing environment for aircraft maintenance. Paper presented at the Proceedings of the 2004 ACM Symposium on Applied Computing, Nicosia, Cyprus, 14-17 March.

Lyytinen, K. \& Yoo, Y. (2002a) Issues and challenges in ubiquitous computing. Communications of the $A C M, 45,63-65$.

Lyytinen, K. \& Yoo, Y. (2002b) Research commentary: the next wave of nomadic computing. Information Systems Research, 13, 377-388.

Mathiassen, L. (2002) Collaborative practice research. Information Technology and People, 15, 321-345. Miles, M.B. \& Huberman, A.M. (1994) Qualitative Data Analysis: An Expanded Sourcebook. Sage, London, UK.

Müller, C.D. \& Zimmermann, H.-D. (2003) Beyond mobile: research topics for upcoming technologies in the insurance industry. Paper presented at the Proceeding of the 36th Hawaii International Conference on System Sciences, HI, USA, 5-9 January. 
Normann, R. \& Ramirez, R. (1993) From value chain to value constellation: designing interactive strategy. Harvard Business Review, 71, 65-77.

Olaisen, J. (1991) Pluralism or positivistic trivialism: important trends in contemporary philosophy of science. In: Information Systems Research: Contemporary Approaches and Emergent Traditions, Nissen, H.-E.,

Klein, H.K. \& Hirschheim, R. (eds), pp. 235-265. Elsevier Science Publishers, BV, North Holland.

Orlikowski, W.J. \& Baroudi, J.J. (1991) Studying information technology in organization: research approaches and assumptions. Information Systems Research, 2, 1-28.

Österle, H. (2001) Enterprise in the Information Age. In: Business Networking: Shaping Collaboration Between Enterprises, Österle, H., Fleisch, E. \& Alt, R. (eds), pp. 17-54. Springer, Berlin, Germany.

Peppard, J. (2001) Bridging the gap between the IS organization and the rest of the business: plotting a route. Information Systems Journal, 11, 249-270.

Porter, M. (1985) Competitive Advantage: Creating and Sustaining Superior Performance. Free Press, New York, NY, USA.

Porter, M. (2001) Strategy and the internet. Harvard Business Review, 79, 63-78.

Stabell, C.B. \& Fjeldstad, Ø.D. (1998) Configuring value for competitive advantage: on chains, shops, and networks. Strategic Management Journal, 19, 413-437.

Stanoevska-Slabeva, K. \& Heitmann, M. (2003) Impact of mobile ad hoc networks on the mobile value system. Paper presented at the 2nd International Conference on Mobile Business (ICMB), Vienna, Austria, 23 June 2003. 
Strassner, M. \& Schoch, T. (2002) Today's impact of ubiquitous computing on business processes. Paper presented at the First International Conference on Pervasive Computing (2002), Zurich, Switzerland, August.

Walker, R.H. \& Craig-Lees, M. (1999) Technology-enabled service delivery: reconciling managerial and customer perspectives. Paper presented at The Ninth Annual World Marketing Congress, Qawra, Malta, 23-26 June.

Walker, R.H. \& Craig-Lees, M. (2000) Technology-enabled service delivery: at risk of compromising the customer-service provider connection? In: Advances in International Marketing, Cavusgil, S.T. \& McNaughton, R.B. (eds), pp. 305-322. JAI Press, Greenwich, CT, USA. Walsham, G. (1993) Interpreting Information Systems in Organizations. Wiley: Chichester, UK.

Yin, R.K. (1989) Case Study Research: Design and Methods. Sage, Newbury Park, CA, USA.

Yoo, Y. \& Lyytinen, K. (2003) Measuring the consequences of ubiquitous computing in networked organizations. Sprouts: Working Papers on Information Environments, Systems and Organizations, 3, 188- 201. 